\section{RECUPERAR LA CIUDAD}

El Seminario Internacional sobre "Revitalización de Cascos Urbanos Deteriorados", organizado por el Ministerio de Obras Públicas y la Municipalidad de Santiago de Chile, reunió a expertos de varios países en torno al tema de la recuperación de estas áreas. La autora del artículo nos presenta las principales conclusiones de este seminario que se celebró en la ciudad capital chilena, en el mes de noviembre de 1992. De España participaron, entre otros, Antonio Serrano R., Director General de la DGPTU del MOPT; Rodolfo García de Pablos, de la Comunidad Autónoma de Madrid; Pío García Escudero, del Ayuntamiento de Madrid; y Ángel Sorrivas, del Ayuntamiento de Barcelona. El presente texto se reproduce por cortesía de "Cuadernos" publicación de FUNDICOT, Madrid.

\section{INTRODUCCIÓN}

El abandono de las áreas centrales de la ciudad moderna ha sido un común denominador para países europeos y americanos. En efecto, si bien las causas del fenómeno pueden ser diferentes, los resultados tienen mucho en común: deterioro generalizado de la edificación, población envejecida, marginalidad e inseguridad ciudadana, terciarización, etc.

El Municipio de Santiago es un fiel representante de este esquema, aunque paradójicamente presenta innegables ventajas comparativas en cuanto a su localización y accesibilidad, en sus instalaciones de servicios y redes de infraestructura, ha venido sufriendo desde los años 50 un claro proceso de pérdida de población, corriendo el riesgo de transformar su carácter residencial a causa de la terciarización. Este proceso fue ampliamente favorecido por la política urbana desarrollada por el gobierno militar que, con una concepción mercantilista en la regulación del suelo urbano ("el suelo no es un recurso escaso"), favoreció los criterios expansionistas en el desarrollo de la ciudad.

Con el retorno a la democracia y el consiguiente cambio de actores, se busca desarrollar nuevas tendencias urbanísticas que pretenden dar solución a los problemas de la ciudad de una forma más integradora y coherente.

La democratización de las instituciones es uno de los principales objetivos del nuevo gobierno y en ese sentido, la Municipalidad de Santiago realizó un programa sobre Municipio y Participación que buscaba incorporar a la ciudadanía en la definición de lineamientos para el desarrollo comunal. De esta experiencia surge un objetivo prioritario, cual es RENOVAR SANTIAGO, afirmando el rol residencial de la comuna, apoyando las actividades económicas y de servicios compatibles con la actividad residencial y aumentando la calidad de vida de la población. Es en este espíritu que se organiza, bajo mi coordinación, un Encuentro sobre Revitalización de Cascos Urbanos.

Esencialmente, la idea consistía en examinar la experiencia realizada en ESPAÑA sobre políticas de Rehabilitación Urbana en los últimos diez años y las incipientes iniciativas que se están llevando a cabo en CHILE. Para ello, fueron invitados varios expertos y técnicos de la Administración pública española, quienes, junto a sus homólogos chilenos, a lo largo de una semana, debatieron y reflexionaron sobre las posibilidades de desarrollar una política rehabilitadora en forma sistemática y efectiva para las ciudades chilenas.

Como colofón a la participación de especialistas españoles, la delegación redactó un documento de conclusiones que sin duda será de gran utilidad a la hora de profundizar sobre la importancia de formular una política de rehabilitación urbana en Chile y sobre los requerimientos que estos implicará. Lo medular de estas conclusiones está comprendido en los párrafos siguientes. Se ha destacado la importancia de diferenciar en cuatro frentes la resolución de estos problemas: a) Visión de conjunto.

b) Objetivos de un Plan de Revitalización.

c) Propuestas concretas de intervención y gestión.

d) Promoción y difusión de las operaciones.

\section{VISIÓN DE CONJUNTO}

Entendemos imprescindible al abordar los problemas y diferentes soluciones de la Comuna de Santiago, el garantizar y priorizar las futuras acciones bajo una óptica de globalidad, aspecto que no se nos escapa, ya es tenido en cuenta por las autoridades chilenas, pero que creemos muy necesario reforzar para garantizar qué equipamientos o servicios supramunicipales, puedan ser llevados a cabo superando el ámbito sectorial o departamental.

El medio ambiente, la red viaria, los espacios libre metropolitanos, el río y la política de vivienda deberán obedecer a objetivos de conjunto: un esquema territorial, o unas directrices de intervención regional, que a modo de planta revivan como garantías de cualquier actuación municipal. Las experiencias así desarrolladas en España (Madrid o Barcelona), que se han expuesto a lo largo de estas jornadas, pueden ser de gran utilidad en este arranque y programación de actuaciones.

\section{OBJetivos de Un PLAN de REVITALIZACIÓn DE COMU- NAS Y BARRIOS}

Entendemos la revitalización, Social Urbana y Económica, como una contribución a la labor de construcción de la ciudad. Cuatro líneas de acción deben presidir este plan de revitalización:

- Superar las ideas conservacionistas o restauradoras restrictivas e insensibilizadoras, respetando aquello que por sus valores merece serlo, persiguiendo actuaciones de renovación o nueva edificación que dinamicen el proceso.

- Definir claramente los límites de actuación entre lo público y lo privado, interviniendo decididamente las administraciones en lo público y regulado e incentivando lo privado, dentro de un noble espíritu de corresponsabilidad.

- Dotarse de instrumentos normativos que determinan pautas urbanísticas, arquitectónicas, ambientales, de protección y de calidad mínima de la edificación.

- Dotarse de mecanismos de gestión y financiación para el desarrollo de los procesos.

\section{PROPUESTAS GENERALES DE INTERVENCIÓN}

El problema de la Comuna de Santiago, entendida como una parte del centro-ciudad, significa:

- Comprenderlo como un aspecto del problema urbano en sus términos reales $y$, por tanto, como un reto residencial y de calidad de vida, así como de uso de un patrimonio.

- Se trata de garantizar el control eficaz de los procesos de transformación de la ciudad, en relación a las características singulares del espacio urbano del Centro Histórico.

Consideramos como caminos a seguir la elaboración de los siguientes trabajos:

- Redacción de un planteamiento específico de carácter global, para la revitalización del Centro Histórico de Santiago, enmarcado dentro del Plan General para la Comuna, que analice los diferentes problemas existentes en la actualidad, y proponga las distintas soluciones, siempre desde un criterio de interrelación (salvación de obstáculos, vía norte-sur, solución de accesos).

\section{DIFUSIÓN Y PROMOCIÓN DE LA OPERACIÓN}

Es importante conseguir la identificación de los distintos sectores sociales, profesionales $y$, sobre todo, del colectivo de habitantes de la ciudad 
de Santiago en el proceso de revitalización y recuperación del casco antiguo. Para ello, la mejor vía es el establecimiento de campañas específicas de difusión en los medios profesionales de comunicación, centros escolares, lugares de reunión, etc. de exposiciones, publicaciones, conferencias, mesas redondas, concursos en las escuelas y similares, para mostrar tanto un pasado histórico brillante como un presente delicado $y$, sobre todo, un futuro atractivo y posible.

La historia de la persona va indisolublemente ligada al escenario donde desarrolla su vida, y la pérdida de parte de este escenario supone la desaparición de parte de su infancia o su pasado.

- Establecimiento de una necesaria coordinación interadministración que optimice, tanto el empleo de los recursos disponibles, como la fluidez del desarrollo del proceso.

- Potenciar el papel de la Corporación para el Desarrollo de Santiago como Organismo impulsor del proceso y coordinador de los actores y recursos necesarios.
En el convencimiento de que este proceso es realizable e irreversible, es necesario abordar una primera experiencia piloto que demuestre su viabilidad e incentive la continuación del mismo.

Al respecto, es necesario considerar que las medidas que se toman además de las urbanísticas, han de buscar revitalizar y potenciar la actividad socioeconómica de las áreas más deprimidas.

También, que la inversión ha de ser choque, concentrada en espacio y tiempo, para que efectúe un efecto multiplicador y dinamice la inversión privada.

Establecer relaciones con Organismo Internacionales relacionados tanto en la Protección del Patrimonio/UNESCO, de la Corporación Internacional de Vivienda, Medio Ambiente, etc., buscando su apoyo institucional para este proceso.

Verónica Serrano Madrid

Especialista en Rehabilitación del Patrimonio

\section{CLASIFICACIÓN SISTEMÁTICA GENERAL PARA LA CONSERVACIÓN Y RESTAURACIÓN DE BIENES MUEBLES}

Se publica a continuación el comentario que, a raíz del Editorial del Boletín Informativo n. ${ }^{\circ}$, nos hiciera llegar el Sr. Decano del Colegio Oficial de Doctores y Licenciados en Bellas Artes y Profesores de Dibujo de Sevilla.

Estudiar y analizar el contenido pormenorizado de la Clasificación Sistemática para la Conservación y Restauración de Bienes Muebles significa reflexionar sobre la valoración tan profunda y completa que ha llevado a cabo la Dirección General de Bienes Culturales a través del Servicio de Conservación y Restauración.

Como Máxima representación del Colectivo de los profesionales de la Conservación y Restauración de Bienes Muebles de Andalucía, englobados en el Ilustre Colegio Oficial de Doctores y Licenciados en Bellas Artes y Profesores de Dibujo debo recapacitar sobre la significación de este ordenamiento en las materias de los Bienes Muebles.

Partimos del principio de una profesión cuyo reconocimiento e importancia es considerada cada vez más en el nivel social y profesional que se merece. Partimos de un reconocimiento técnico y científico necesario para el estudio de los Bienes Culturales. Partimos como una profesión integrante en grupos interdisciplinares o como directores y coordinadores de los mismos. Se aleja cada vez más el concepto artesanal para profundizar en el estudio y análisis del material a tratar.

La Consejería de Cultura y Medio Ambiente de la Junta de Andalucía, pionera de la legislación, normalización y ordenamiento de la Conservación y Restauración de los Bienes Muebles en toda España, toma conciencia de las necesidades y exigencias de este Colectivo Profesional.

Ya en la Ley 1/1991 de Patrimonio Histórico de Andalucía se crea la obligación de un Proyecto de Conservación ante una intervención en el Patrimonio Histórico de Andalucía. Se crean unas pautas de contenido de ese Proyecto que más adelante se van a desarrollar en el Reglamento de Conservación y Restauración.
Los Primeros Proyectos de Conservación y Restauración de los Bienes Muebles, con un profundo desarrollo, parten de Andalucía. Pero ser pionera en la materia significa ir tropezando en todos los vacíos que se encuentren en el camino.

Era necesaria la creación de un banco de Precios, imprescindible para la regulación de precios y tarifas de materias y materiales que el profesional va a desarrollar. Aún en la semejanza de criterios, aún en la semejanza de materiales a emplear, aún en la semejanza de necesidades en la intervención en los Bienes Muebles, faltaba una ordenación de ideas y conceptos, puesto que los Proyectos desarrollados por los profesionales son muy dispares entre sí.

La idea de la realización de un Banco de Precios por parte del Departamento de Bienes Muebles del Servicio de Conservación y Restauración que de homogeneidad y ofrezca pautas de comportamientos similares es, sin duda, una acción inmejorable. Pero el Banco de Precios, al igual que su homólogo Banco de Precios de la Construcción, parte de la necesidad de realizar una Clasificación Sistemática General que garantice todas aquellas posibilidades técnicas, científicas y complementarias que un Conservador-Restaurador puede encontrar a la hora de realizar un Proyecto.

Reflexionando sobre el contenido, y siendo bastante coherente en la materia, puedo decir que es la Clasificación más exhaustiva y completa que se podía desarrollar en este tema. Imagino que es mejorable en el futuro, ya que se trata de una Clasificación Sistemática bastante abierta. La labor realizada por los técnicos del Departamento de Bienes Muebles y por su coordinador Rafael Lucas Ruiz es de elogio. La claridad con que se desarrolla, el ordenamiento, la división de los Capítulos, Subcapítulos y Apartados, las claves y numeración con las que se definen hacen que su contenido tanga buena asimilación y buen entendimiento.

Esperemos que todos los profesionales tengamos acceso a esta Clasificación Sistemática, que sin duda será bien aceptada por nuestro Colectivo y que sea el principio del tan esperado Banco de Precios para la Conservación y Restauración de los bienes Muebles.

Mauricio J. López Madroñero Decano del Colegio Oficial de Doctores y Licenciados en Bellas Artes de Sevilla 